\title{
PENGARUH APLIKASI BEBERAPA TARAF KONSENTRASI FORMULASI KERING Metarhizium anisopliae (Metchnikoff) Sorokin ISOLAT YOGYAKARTA TERHADAP MORTALITAS KEPIK PENGISAP BUAH KAKAO (Helopeltis spp.) DI LABORATORIUM
}

\author{
Erwan Erdiyanto, Purnomo*, Lestari Wibowo \& Nur Yasin \\ Jurusan Agroteknologi, Fakultas Pertanian Universitas Lampung, \\ Jl. Soematri Brodjonegoro, No.1, Bandar Lampung 35145 \\ E-mail: Erwanerdiyanto@gmail.com \\ *Penulis Korespondensi, E-mail: purjomo@yahoo.com
}

\begin{abstract}
ABSTRAK
Hama pengisap buah kakao (Helopeltis spp.) merupakan hama penting yang menyerang tanaman kakao. Pengendalian hama menggunakan insektisida selama ini masih kurang memuaskan. Selain itu, petani dalam menggunakan insektisida pada umumnya melebihi dosis anjuran. Penggunaan pestisida yang tidak tepat ini dapat mengganggu ekosistem, keseimbangan populasi musuh alami, menyebabkankan resurjensi atau ledakan hama serta resistensi hama. Untuk itu diperlukan pengendalian yang aman dan ramah lingkungan. Salah satu alternatif yang mencakup kedua hal ini yaitu penggunaan agensia pengendali hayati, seperti jamur entomopatogen, yang masih perlu untuk diteliti. Tujuan penelitian ini adalah untuk mengetahui pengaruh beberapa taraf konsentrasi formulasi kering Metarhizium anisopliae isolat Yogyakarta terhadap mortalitas hama kepik penghisap buah kakao (Helopeltis spp.). Percobaan disusun dalam Rancangan Acak Kelompok yang terdiri atas 5 perlakuan. Pengelompokan berdasarkan 3 waktu aplikasi yang berbeda. Setiap unit percobaan terdiri atas 20 ekor imago Helopeltis spp. Perlakuan terdiri atas kontrol (P0), aplikasi formulasi kering M. anisopliae dengan konsentrasi $5 \mathrm{~g} \mathrm{l}^{-1}$ air (P1), aplikasi formulasi kering $M$. anisopliae dengan konsentrasi $10 \mathrm{~g} \mathrm{l}^{-1}$ air (P2), aplikasi formulasi kering M. anisopliae dengan konsentrasi $15 \mathrm{~g} \mathrm{l}^{-1}$ air (P3), dan aplikasi formulasi kering $M$. anisopliae dengan konsentrasi konsentrasi $20 \mathrm{~g} \mathrm{l}^{-1}$ air (P4). Data yang didapatkan dianalisis ragamnya dan dilanjutkan dengan Uji BNT dengan taraf nyata 1 atau 5\%. Hasil penelitian menunjukkan bahwa aplikasi formulasi kering M. anisopliae isolat Yogyakarta menyebabkan mortalitas pada Helopeltis spp. Mortalitas Helopeltis spp. tertinggi pada 10 hsa terjadi pada perlakuan aplikasi formulasi kering M. anisopliae dengan konsentrasi $15 \mathrm{~g} \mathrm{l}^{-1}$ air sebesar $88,24 \%$, dengan periode letal 4,21 hari yang tidak berbeda nyata dengan konsentrasi $20 \mathrm{~g} \mathrm{l}^{-1}$ air.
\end{abstract}

Kata kunci: formulasi kering, Helopeltis spp., Metarhizium anisopliae, mortalitas

\section{PENDAHULUAN}

Kakao (Theobroma cacao L.) merupakan salah satu komoditas perkebunan yang peranannya cukup penting bagi perekonomian nasional. Hal ini dapat dilihat dari kecenderungan permintaan pasar dunia yang semakin meningkat dengan rata-rata 1.500 .000 ton per tahun.

Dalam kesuksesan perkembangan perkebunan kakao Indonesia, perkebunan kakao di Indonesia pun dihadapkan pada beberapa permasalahan sehingga produktivitasnya belum maksimal.Salah satu permasalahan dalam perkebunan kakao adalah adanya serangan hama dan patogen pada tanaman kakao. Salah satu hama penting yang menyerang kakao adalah kepik pengisap buah kakao (Helopeltis spp.) karena nimfa dan imagonya sangat merusak buah kakao. Helopeltis spp. dapat menimbulkan kerugian yang cukup besar untuk perkebunan kakao. Untuk itu, diperlukan upaya pengendalian hama, agar dapat menekan kerugian bagi perkebunan kakao di Indonesia.

Selama ini upaya pengendalian hama dengan menggunakan insektisida yang dilakukan oleh petani masih kurang memuaskan, terutama dalam menekan populasi Helopeltis spp.. Selain itu, petani dalam menggunakan insektisida pada umumnya melebihi dosis anjuran, akibatnya dapat mengganggu ekosistem dan kesehatan manusia. Penggunaan insektisida yang tidak sesuai akan mengganggu keseimbangan populasi musuh alami, menyebabkan resurjensi atau ledakan hama serta resistensi hama (Supriyadi, 1999 dalam Herlinda et al., 2008a). Untuk itu diperlukan pengendalian yang aman dan ramah lingkungan. Salah satu alternatif yang mencakup dua hal tersebut yaitu penggunaan agensia pengendali hayati, seperti jamur entomopatogen.

Salah satu jamur entomopatogen yang potensial dalam mengendalikan Helopeltis spp. adalah Metarhizium anisopliae. Menurut Wiedemann (1984) 
dalam Hasibuan et al.(2009), jamur M. anisopliae mempunyai kemampuan menginfeksi berbagai jenis serangga termasuk Helopeltis spp.

Jamur Metarhizium sp. dilaporkan dapat diproduksi secara masal dan diformulasikan sebagai bioinsektisida baik dalam bentuk padat maupun cair (Alves et al., 2002; Geden \& Steinkraus, 2003 dalam Efendy, 2010). Menurut Prayogo et al. (2005) Metarhizium sp. dapat diproduksi secara masal pada media instan, seperti SDB (Saborroud Dextrose Broth) atau SDA (Saborroud Dextrose Agar).

Selain substrat yang digunakan dalam memproduksi jamur, bahan pembawa (carrier) dapat juga digunakan untuk pembuatan formulasi bioinsektisida, karena dapat berperan dalam mempertahankan keefektifan formulasi bila telah berfungsi sebagai bahan aktif bioinsektisida. Menurut Hasyim (2006 dalam Efendy, 2010) tepung jagung dan tepung beras dapat digunakan dalam pembuatan formulasi bioinsektisida berbahan aktif Beauveria bassiana. Jamur Metarhizium sp. diketahui memiliki sifat yang sama dengan $B$. bassiana, diharapkan jenis bahan pembawa tersebut dapat dikembangkan juga pada jamur Metarhizium sp. (Prayogo et al. , 2005). Untuk dapat diaplikasikan secara mudah dan praktis oleh petani, maka suatu agensia hayati perlu dibuat dalam bentuk kering yang tahan lama.

Berdasarkan identifikasi dan perumusan masalah yang telah dibuat, maka dapat dirumuskan tujuan penelitian adalah untuk mengetahui pengaruh beberapa taraf konsentrasi formulasi kering $M$. anisopliae isolat Yogyakarta terhadap mortalitas hama kepik pengisap buah kakao (Helopeltis spp.).

\section{METODE PENELITIAN}

Penelitian ini dilaksanakan di Laboratorium Hama Tanaman Fakultas Pertanian Universitas Lampung pada bulan September sampai dengan Desember 2012. Percobaan disusun dalam Rancangan Acak Kelompok yang terdiri atas 5 perlakuan. Setiap perlakuan terdiri dari 3 kelompok waktu aplikasi yang berbeda. Setiap unit percobaan terdiri dari 20 ekor imago Helopeltis spp.. Perlakuan terdiri atas kontrol (P0), aplikasi formulasi kering $M$. anisopliae dengan konsentrasi 5 $\mathrm{g} \mathrm{l}^{-1}$ air (P1), $10 \mathrm{~g} \mathrm{l}^{-1}$ air (P2 $15 \mathrm{~g} \mathrm{l}^{-1}$ air (P3), $20 \mathrm{gl}^{-1}$ air (P4). Data yang didapatkan dianalisis ragam dan dilanjutkan dengan Uji BNT dengan taraf nyata 5\% kemudian dilakukan analisis Probit untuk menentukkan $\mathrm{LC}_{50}$.

Pembiakan serangga ini dilakukan di laboratorium, yaitu dengan menggunakan mentimun sebagai inang alternatif. Mentimun yang digunakan sebagai pakan alternatif dan media bertelur merupakan mentimun yang segar, tidak cacat secara fisik,ujungnya tidak keriput dan warnanya tidak terlalu hijau. Sebelum pembiakan, terlebih dahulu dilakukan pencarian indukan Helopeltis spp.. Indukan serangga terdiri dari imago dan nimfa Helopeltis spp. yang diambil dari lapangan. Indukan imago dan nimfa dipisahkan dan dimasukkan ke dalam stoples plastik berdiameter $16 \mathrm{~cm}$ dengan tinggi $17 \mathrm{~cm}$ yang telah diletakkan mentimun, lalu ditutup menggunakan kain strimin yang kemudian diikat menggunakan karet gelang. Setiap stoples diisi \pm 20 ekor serangga yang terdiri dari 10 ekor jantan dan 10 ekor betina dan \pm 2 buah mentimun. Mentimun tersebut diganti setiap 2-3 hari sekali. Setiap penggantian mentimun, mentimun-mentimun tersebut diamati pada bagian permukaannya untuk melihat adanya telur Helopelthis spp.. Telur Helopelthis spp. pada mentimun dapat dicirikan dengan adanya seperti benang halus dan kecil pada permukaan mentimun. Kemudian mentimun yang terdapat telur Helopelthis spp. dipisahkan dan ditempatkan pada stoples yang baru \pm 3 buah/stoples, kemudian ditutup dengan kain strimin dan diikat dengan karet gelang dan diberi label tanggal. Setelah telur menetas, maka nimfa dipindahkan ke dalam stoples yang baru dan diberi pakan mentimun yang masih segar. Begitu seterusnya sampai diperoleh imago dengan jumlah yang diperlukan.

Sabouraud Dextrose Agar merupakan media yang mengandung pepton di dalamnya. Satu liter media ini dikomposisikan dari 40 gram dextrose, 5 gram pepton, 5 gram kasein, 15 gram agar dan 1 liter air destilata. Semua larutan dimasukkan ke dalam tabung Erlenmeyer kemudian ditutup menggunakan alumunium foil, dikencangkan dengan karet gelang dan dibungkus plastik tahan panas. Selanjutnya larutan SDA disterilisasi dalam autoclave selama pada suhu $120^{\circ} \mathrm{C}$ selama 20 menit. Setelah itu diangkat dan didiamkan sebentar supaya sedikit lebih dingin. Kemudian larutan SDA dituangkan ke masing-masing petridish dalam ruangan steril (Laminar Air Flow). Tujuan pembuatan media SDA ini adalah sebagai media tumbuh jamur Metarhizium anisopliae.

Isolat $M$. anisopliae yang digunakan adalah isolat dari Yogyakarta (UGM). Kemudian diisolasi guna mempertahankan dan memperbanyak isolat murni. Isolasi dilakukan di laboratorium jurusan Agroteknologi menggunakan media SDA (Saborroud dextrose agar) kemudian melalui tahapan letal selama 1 bulan. Setelah itu, jamur siap digunakan untuk ditumbuhkan kembali pada media beras. 
Pembuatan formulasi kering Metarhizium anisopliae dalam penelitian ini mengacu pada Purnomo et al. (2012). Pembuatan media beras sebagai media perbanyakan jamur Metarhizium anisopliae dilakukan dengan mengukus beras hingga setengah matang $( \pm 10$ menit). Setelah itu, beras dimasukkan ke kantong plastik $( \pm 100 \mathrm{~g})$ lalu disterilkan dengan autoklaf pada suhu 120ÚC, pada tekanan $1 \mathrm{~atm}$, selama 20 menit. Kemudian diangkat, dan setelah media beras tersebut dingin, jamur M. anisopliae diinokulasikan pada media beras. Jamur M. anisopliae yang telah diinokulasikan diletal selama \pm 1 minggu. Dan setelah itu, dikeringkan di dalam lemari pendingin selama \pm 12 hari. Selanjutnya, jamur $M$. anisopliae yang telah tumbuh dalam media beras akan digunakan dalam pembuatan formulasi kering.

Berdasarkan penelitian Purnomo et al. (2012), pembuatan formulasi kering dilakukan dengan mengeringkan Metarhizium anisopliae yang tumbuh pada media beras. Pengeringan dilakukan dengan pengeringan dingin yaitu dengan cara menyimpan di dalam lemari pendingin dengan suhu 5 ÚC selama 12 hari. Biakan $M$. anisopliae yang telah kering selanjutnya diblender hingga menjadi tepung kemudian diayak. Bahan-bahan pembawa seperti, kaolin, zeolit, dan tepung jagung disterilkan dalam oven dengan suhu 80ÚC. Kemudian tepung $M$. anisopliae dengan bahan pembawa dicampurkan di dalam kantong plastik dengan perbandingan seperti pada Tabel 1 . Formulasi kering $M$. anisopliae yang telah jadi, kemudian ditimbang sesuai taraf konsentrasi yang digunakan pada penelitian ini yaitu $5 \mathrm{~g}, 10 \mathrm{~g}, 15 \mathrm{~g}$, dan $20 \mathrm{~g}$. Melalui perhitungan kerapatan spora menggunakan mikroskop dengan tingkat pengenceran $10^{3}$ telah didapatkan kerapatan spora jamur $M$. anisopliae pada setiap 1 gram formulasi kering adalah $14,85 \times 10^{6}$ spora $\mathrm{ml}^{-1}$.

Pengujian formulasi kering berbahan aktif jamur $M$. anisoliae dilakukan dengan cara melarutkan formulasi kering dengan air lalu ditambahkan bahan perata perekat (indostick) sebanyak $1 \mathrm{ml} \mathrm{l}^{-1}$. Taraf konsentrasi dimulai dari $5 \mathrm{~g} \mathrm{l}^{-1}$ air, $10 \mathrm{~g} \mathrm{l}^{-1}$ air, $15 \mathrm{~g} \mathrm{l}^{-1}$ air,dan $20 \mathrm{~g} \mathrm{l}^{-1}$ air formulasi kering berbahan aktif jamur
M. anisoliae. Penentuan konsentrasi formulasi kering jamur $M$. anisoliae didasarkan pada uji pendahuluan yang telah dilakukan sebelumnya, selanjutnya serangga uji Helopeltis spp. yang terdiri dari 20 ekor imago per satu satuan percobaan dimasukkan kedalam botol air mineral yang dipotong bagian atas dan bagian bawahnya, kemudian pada bagian bawahnya ditutup dengan kain strimin dan diikat dengan karet gelang, setelah itu diaplikasikan suspensi menggunakan handsprayer sebanyak 3 kali semprot atau $\pm 3 \mathrm{~m} \mathrm{l}^{-1}$, sesuai dengan tingkat dosis yang telah ditentukan. Kemudian dimasukkan kembali ke dalam toples dan diberi pakan mentimun. Helopeltis spp. yang mati kemudian diletakkan pada cawan petri berisi kapas/ kertas tissu yang lembab. Dan didiamkan serta diamati setiap hari hingga terlihat adanya jamur $M$. anisopliae di sekitar tubuh serangga uji Helopelthis spp..

Pengamatan jumlah Helopeltis spp. yang mati akibat terinfeksi jamur $M$. anisoliae dilakukan setiap 24 jam sekali selama 10 hari setelah aplikasi. Menurut Rustama et al. (2008) mortalitas (kematian) serangga dapat dihitung menggunakan rumus seperti berikut :

$$
M=\frac{\sum n}{\sum N} x 100 \%
$$

dengan $\mathrm{M}$ adalah mortalitas serangga (\%), n dalah jumlah serangga yang mati (ekor), $\mathrm{N}$ adalah jumlah serangga yang diuji (ekor).

Apabila terdapat kematian Helopeltis spp. pada kontrol $>20 \%$ maka persentase kematian terkoreksi dihitung berdasarkan rumus Abbot (1925) dalam Wardhana et al. (2009).

$$
\mathrm{Pt}=\frac{(\mathrm{Po}-\mathrm{Pc})}{(100-\mathrm{Pc})} \times 100
$$

dengan Pt adalah \% kematian terkoreksi, Po adalah \% kematian pada perlakuan, dan Pc adalah \% kematian pada kontrol.

Menurut Susilo et al. (1993) dalam Indriyati (2009) periode letal merupakan jangka waktu sejak inokulasi sampai terjadinya kematian inang. Nilai periode

Tabel 1. Komposisi formulasi kering jamur M. anisopliae

\begin{tabular}{lc}
\hline Bahan & Jumlah $(\mathrm{g})$ \\
\hline Tepung biomassa spora M. anisopliae & 40 \\
Kaolin & 20 \\
Zeolit & 20 \\
Tepung jagung & 20 \\
\hline Total & 100 \\
\hline
\end{tabular}


letal M. anisopliae terhadap serangga uji dapat dihitung menggunakan rumus (Susilo et al., 1993 dalam Indriyati, 2009) :

$$
\text { Periode Letal }(\mathrm{T})=\left[\sum\left(\mathrm{H}_{\mathrm{i}} \times \mathrm{M}_{\mathrm{i}}\right)\right] /\left[\sum\left(\mathrm{M}_{\mathrm{i}}\right)\right]
$$

dengan $\mathrm{F}$ adalah periode letal, Hi adalah hari ke-i, dan Mi adalah jumlah serangga mati (ekor) karena terinfeksi jamur M. anisopliae pada hari ke- $\mathrm{i}$

\section{HASIL DAN PEMBAHASAN}

Hasil penelitian menunjukkan bahwa aplikasi $M$. anisopliae secara nyata menyebabkan mortalitas Helopeltis spp.. Data mortalitas Helopeltis spp. selengkapnya tertera pada Tabel 2.

Hasil penelitian menunjukkan bahwa aplikasi $M$. anisopliae menyebabkan mortalitas Helopeltis spp. Mortalitas Helopeltis spp. mulai terjadi sejak pengamatan $1 \mathrm{hsa}$, namun tingkat mortalitas tersebut masih rendah dan belum menyebabkan hasil yang nyata. Pada pengamatan hari ke-2 telah terlihat terjadi peningkatan mortalitas Helopeltis spp. dan telah terlihat pengaruh yang nyata akibat dari aplikasi $M$. anisopliae (Tabel 2). Pada pengamatan selanjutnya mortalitas terus meningkat. Pada hari ke-10 hsa, mortalitas Helopeltis spp. pada perlakuan aplikasi formulasi kering $M$. anisopliae dengan konsentrasi $15 \mathrm{~g} \mathrm{l}^{-1}$ air sebesar
$88,24 \%$ yang secara nyata lebih tinggi dibandingkan dengan konsentrasi yang lebih rendah, namun tidak berbeda nyata dengan mortalitas pada perlakuan dengan konsentrasi $20 \mathrm{~g} \mathrm{l}^{-1}$ air.

Berdasarkan hasil dari pengamatan di atas (Tabel 2), dapat dilihat bahwa semakin tinggi konsentrasi formulasi kering Metarhizium anisopliae yang diaplikasikan, semakin tinggi juga persentase mortalitas Helopeltis spp. Pada perlakuan aplikasi formulasi kering $M$. anisopliae dengan konsentrasi $15 \mathrm{~g} \mathrm{l}^{-1}$ air mortalitas Helopeltis spp. dengan kerapatan spora $14,8510^{6}$ spora $\mathrm{ml}^{-1}$ mencapai $88,24 \%$.

Analisis probit digunakan untuk mendapatkan nilai $\mathrm{LC}_{50} . \mathrm{LC}_{50}$ merupakan suatu konsentrasi yang dapat menyebabkan kematian 50\% pada serangga hama yang diuji dalam jangka waktu tertentu (Negara,2003). Berdasarkan hasil analisis probit pada beberapa taraf konsentrasi formulasi kering jamur $M$. anisopliae yang diujikan terhadap Helopeltis spp. menunjukkan, bahwa nilai $\mathrm{LC}_{50}$ sebesar 2,64 yang berarti untuk mematikan 50\% serangga Helopeltis spp. diperlukan aplikasi formulasi kering $M$. anisopliae sebanyak $2,64 \mathrm{~g} \mathrm{l}^{-1}$ air.

Dari hasil pengamatan menunjukkan bahwa pada perlakuan P1, P2, P3 dan P4 memiliki periode letal yang tidak berbeda nyata, yaitu antara 4,08 hari sampai 4,21 hari (Tabel 3). Dari Tabel 3 dapat diambil kesimpulan bahwa jamur M. anisopliae membutuhkan waktu untuk mematikan Helopeltis spp.

Tabel 2. Nilai tengah mortalitas terkoreksi Helopeltis spp.

\begin{tabular}{lcccccccccc}
\hline & \multicolumn{10}{c}{ Mortalitas (\%) terkoreksi Helopeltis spp. pada } \\
\cline { 2 - 10 } Perlakuan & 1 hsa & 2 hsa & 8 hsa & 8 hsa & 5 hsa & 6 hsa & 7 hsa & 8 hsa & 9 hsa & 10 hsa \\
\hline \multirow{2}{*}{ P0 } & 0,00 & 0,00 & 0,00 & 0,00 & 0,00 & 0,00 & 0,00 & 0,00 & 0,00 & 0,00 \\
& $\mathrm{a}$ & $\mathrm{a}$ & $\mathrm{a}$ & $\mathrm{a}$ & $\mathrm{a}$ & $\mathrm{a}$ & $\mathrm{a}$ & $\mathrm{a}$ & $\mathrm{a}$ & $\mathrm{a}$ \\
$\mathrm{P} 1$ & 6,67 & 18,33 & 31,58 & 43,86 & 45,61 & 55,56 & 59,94 & 63,83 & 66,67 & 66,67 \\
& $\mathrm{a}$ & $\mathrm{a}$ & $\mathrm{b}$ & $\mathrm{b}$ & $\mathrm{b}$ & $\mathrm{b}$ & $\mathrm{b}$ & $\mathrm{b}$ & $\mathrm{b}$ & $\mathrm{b}$ \\
$\mathrm{P} 2$ & 15,00 & 20,18 & 29,82 & 42,11 & 56,14 & 64,52 & 74,46 & 83,01 & 78,43 & 78,43 \\
& $\mathrm{~b}$ & $\mathrm{a}$ & $\mathrm{b}$ & $\mathrm{b}$ & $\mathrm{b}$ & $\mathrm{b}$ & $\mathrm{b}$ & $\mathrm{c}$ & $\mathrm{c}$ & $\mathrm{c}$ \\
$\mathrm{P} 3$ & 11,67 & 35,18 & 43.86 & 54,39 & 59,65 & 64,52 & 74,66 & 79,08 & 86,27 & 88,24 \\
& $\mathrm{ab}$ & $\mathrm{b}$ & $\mathrm{b}$ & $\mathrm{b}$ & $\mathrm{b}$ & $\mathrm{b}$ & $\mathrm{b}$ & $\mathrm{b}$ & $\mathrm{cd}$ & $\mathrm{d}$ \\
& 10,00 & 34,91 & 49,12 & 59,65 & 64,91 & 68,23 & 72,90 & 79,19 & 84,31 & 90,20 \\
P4 & $\mathrm{a}$ & $\mathrm{ab}$ & $\mathrm{b}$ & $\mathrm{b}$ & $\mathrm{b}$ & $\mathrm{b}$ & $\mathrm{b}$ & $\mathrm{bc}$ & $\mathrm{c}$ & $\mathrm{d}$ \\
\hline \multirow{2}{*}{ F hit } & 2,78 & 3,46 & 4,36 & 7,58 & 12,49 & 23,36 & 45,25 & 55,09 & 242,28 & 403,33 \\
\hline BNT 5 \% & 11,14 & 25,41 & 29,78 & 27,85 & 24,23 & 19,33 & 15,56 & 15,33 & 7,56 & 6,06 \\
\hline
\end{tabular}

Keterangan: Angka sekolom yang diikuti dengan huruf yang berbeda menunjukkan nilai tengah yang berbeda nyata pada uji BNT $\alpha=0,05 . \mathrm{P} 0=$ Kontrol (tanpa aplikasi formulasi kering $M$. anisopliae), $\mathrm{P} 1=$ Aplikasi formulasi kering $M$. anisopliae konsentrasi $5 \mathrm{~g} \mathrm{l}^{-1}$ air, $\mathrm{P} 2=$ Aplikasi formulasi kering $M$. anisopliae konsentrasi $10 \mathrm{~g} \mathrm{l}^{-1}$ air, $\mathrm{P} 3=$ Aplikasi formulasi kering $M$. anisopliae konsentrasi $15 \mathrm{~g} \mathrm{l}^{-1}$ air, dan $\mathrm{P} 4=$ Aplikasi formulasi kering M. anisopliae konsentrasi $20 \mathrm{~g} \mathrm{l}^{-1}$ air. 
Tabel 3. Periode letal jamur M. anisopliae isolat Yogyakarta

\begin{tabular}{cc}
\hline Perlakuan & Periode letal (hari) \\
\hline P1 & $4,08 \mathrm{a}$ \\
P2 & $4,17 \mathrm{a}$ \\
P3 & $4,19 \mathrm{a}$ \\
P4 & $4,21 \mathrm{a}$ \\
\hline F hit & 0,015 \\
\hline
\end{tabular}

Keterangan: angka-angka yang diikuti dengan huruf yang berbeda menunjukkan nilai tengah yang berbeda nyata pada uji BNT $\alpha=0,05$. P0 = Kontrol (tanpa aplikasi formulasi kering $M$. anisopliae), $\mathrm{P} 1=$ Aplikasi formulasi kering $M$. anisopliae konsentrasi $5 \mathrm{~g} \mathrm{l}^{-1}$ air, $\mathrm{P} 2=$ Aplikasi formulasi kering M. anisopliae konsentrasi $10 \mathrm{~g} \mathrm{l}^{-1}$ air, P3= Aplikasi formulasi kering $M$. anisopliae konsentrasi $15 \mathrm{~g}^{-1}$ air, dan P4 = Aplikasi formulasi kering $M$. anisopliae konsentrasi $20 \mathrm{~g} \mathrm{l}^{-1}$ air.

\section{KESIMPULAN}

Formulasi kering $M$. anisopliae dengan konsentrasi $15 \mathrm{~g} \mathrm{l}^{-1}$ air memiliki mortalitas Helopeltis spp. sebesar $86,27 \%$ yang secara nyata lebih tinggi dibandingkan dengan konsentrasi yang lebih rendah, namun tidak berbeda nyata dengan mortalitas pada perlakuan dengan konsentrasi $20 \mathrm{~g} \mathrm{l}^{-1}$ air, nilai $\mathrm{LC}_{50}$ formulasi kering $M$. anisopliae terhadap Helopeltis spp. adalah sebesar 2,64 $\mathrm{g} \mathrm{l}^{-1}$ air, periode letal jamur $M$. anisoliae isolat Yogyakarta tidak berbeda nyata antar perlakuan yaitu antara aplikasi formulasi kering $M$. anisopliae konsentrasi $5 \mathrm{~g} \mathrm{l}^{-1}$ air 4,08 hari, aplikasi formulasi kering $M$. anisopliae konsentrasi $10 \mathrm{~g} \mathrm{l}^{-1}$ air 4,17 hari, aplikasi formulasi kering $M$. anisopliae konsentrasi $15 \mathrm{~g} \mathrm{l}^{-1}$ air 4,19 hari dan aplikasi formulasi kering M. anisopliae konsentrasi $20 \mathrm{~g} \mathrm{l}^{-1}$ air 4,21 hari.

\section{DAFTAR PUSTAKA}

Atmadja, W.R., Wahyono, T.E., Dhalimi, A. 2010. Aplikasi Beberapa Strain Beauveria bassiana Terhadap Helopeltis antonii Sign Pada Bibit Jambu Mete. Bul. Littro 21(1): 37-42.

Brousseau, C, G. Charpentier, \& S. Belloncik. 1996. Susseptibility of Spruce Budworm, Choristoneura fumiferana Clemens, to Destruxins, Cyclodepsipeptidic Mycotoxin of Metarhizium anisopliae. Journal of Invertebrata Pathology 68: 180-182.

Effendy T.A. 2010. Uji toksisitas bioinsektisida jamur Metarhizium sp. berbahan pembawa bentuk tepung untuk mengendalikan Nilaparvata lugens (Stal.) (Homoptera: Delphacidae) di tanaman padi. Prosiding Seminar Hasil Penelitian Bidang
Pertanian Pertanian Terintegrasi Menuju Milenium Development Goal (MDGS), UNSRI, Palembang, 20-21 Oktober 2010. hlm 84-93.

Hasibuan, R., Crhistalia, N., Susilo, F.X., \& Yasin, N. 2009. Potential impact of Metarhizium anisopliaeo on The Diamondback Mpth (Lepidoptera : Plutellidae) and its parasitoid Diadegma semiclausum (Hymenoptera : Ichneumonidae). J. HPT Tropika 9(2): 99-108.

Herlinda, S., Irsan, C., \& Hartono. 2008a. Efikasi Bioinsektisida Formulasi Cair Berbahan Aktif Beauveria bassiana (Bals.) Vuill dan Metarhizium sp. Pada Wereng Punggung Putih (Sogatella furcifera Horv.). Seminar Nasional dan Kongres PATPI (Perhimpunan Ahli Teknologi Pangan Indonesia) 2008, Palembang 14-16 Oktober 2008.

Herlinda, S., Mulyati, S.I., \& Suwandi. 2008b. Jamur Entomopatogen Berformulasi Cair sebagai Bioinsektisida untuk Pengendali Werang Coklat. Agritrop 27(3): 119-126.

Indriyati. 2009. Virulensi Jamur Entomopatogen Beauveria bassiana (Balsamo) Vuillemin (Deutromycotina: Hyphomycetes) Terhadap Kutudaun (Aphis spp.) dan Kepik Hijau (Nezara viridula). J. HPT Tropika 9(2): 92-98.

Negara, A. 2003. Penggunaan Analisis Probit Untuk Pendugaan Tingkat Kepekaan Populasi Spodoptera exigua Terhadap Deltametrin di Daerah Istimewa Yogyakarta. Informatika Pertanian 12: 1-9. 
Rustama, M. M., Melanie., \& Irawan, B. 2008. Patogenisitas Jamur Entomopatogen Metarhizium anisopliae Terhadap Crocidolomia pavonana Fab. Dalam Kegiatan Studi Pengendalian Hama Terpadu Tanaman Kubis Dengan Menggunakan Agensia Hayati. Laporan Penelitian. Universitas Padjadjaran. Jawa Barat.

Prayogo Y, Tengkano W \& Marwoto. 2005. Prospek cendawan entomopatogen Metarhizium anisopliae untuk mengendalikan ulat grayak Spodoptera litura pada kedelai. J. Litbang. Pertanian 24:19-26.
Purnomo, Aeny, TN., \& Fitriyana, Y. 2012. Pembuatan dan Aplikasi Formulasi Kering Tiga Jenis Agensia Hayati Untuk Mengendalikan Hama Pencucuk Buah dan Penyakit Busuk Buah Kakao. Laporan Penelitian Hibah Bersaing. Universitas Lampung. Bandar Lampung.

Wardhana, A.H., Husein, H., \& Manurung, J. 2005. Efektifitas Biji Srikaya (Annona squamosa L) dengan pelarut air, Metanol, Heksan terhadap mortalitas Larva Caplak Boophilus microplus secara In Vitro. J.Ilmu Ternak dan Veteriner 10(2): 134-142. 